\title{
Clinico-Morphological Profile and Receptor Status in Breast Cancer Patients in a South Indian Institution
}

\author{
Saptarshi Ghosh ${ }^{1 *}$, Shreyasee Sarkar ${ }^{2}$, Samara Simhareddy ${ }^{3}$, Sivasankar Kotne ${ }^{1}$, \\ Pammidimukkala Bramh Ananda Rao ${ }^{1}$, Satya Prakash Venkatachalam Turlapati ${ }^{2}$
}

\begin{abstract}
Background: Breast cancer is the most common malignancy in women worldwide and the second most common cancer in females in India. Receptor status may be important for survival. Objective: To analyse and correlate the clinical and morphological parameters with receptor status in breast carcinoma patients in a tertiary care institution in Southern India. Materials and Methods: This retrospective study involved 320 patients of breast cancer diagnosed in an oncology hospital over a period of 31/2 years. Data was analysed using SPSS Version 21. Results: Some $60.6 \%$ patients with breast carcinomas belonged to the age group of 40 to 60 years. The most common histological type was infiltrating ductal carcinoma, not otherwise specified, accounting for $84.4 \%$ of patients. On immunohistochemistry, estrogen receptor (ER) and progesterone receptor (PR) were expressed in $56.3 \%$ and $53.1 \%$ of cases, respectively. Conclusions: Breast cancers in India, a developing country, occur in younger women and tend to be more aggressive with lower rates of ER and PR expression and higher histological tumor grades. Both ER and PR status of the tumors had significant associations with the patient age, pathological TNM stage and histological tumor grade.
\end{abstract}

Keywords: Breast cancer - estrogen receptor - progesterone receptor - stage - grade - India

Asian Pac J Cancer Prev, 15 (18), 7839-7842

\section{Introduction}

Breast carcinoma is the most common malignancy in females worldwide (Siegel et al., 2014). It is a leading cause of death in women (Sin ghai $\mathrm{R}$ et al., 2011). At many parts of India, breast carcinoma has now become the most common malignancy replacing cervical cancer, especially in urban India (Murthy et al., 2009).

Breast cancer has many clinical and morphological parameters which alter the prognosis of these patients like gross tumor size, lymph node metastases, histological grade of tumor, tumor necrosis and lymphovascular space invasion (LVSI).

Immunohistochemistry plays a very important role in the prognostication and treatment determination of breast carcinoma patients. But, due to the high cost and decreased availability of these investigations in Indian scenario, it is not routinely carried out in all centres in India.

The current study was initiated to analyse the clinical parameters, morphological profile and hormone receptor status in our breast cancer patients. The estrogen receptor (ER) and progesterone receptor (PR) status were also correlated with the clinico-morphological parameters.

\section{Materials and Methods}

The present study is a retrospective study on breast cancer patients being treated in a tertiary care oncological institute in South India from January 2011 to June 2014. Patients with a histopathologically confirmed diagnosis of breast carcinoma with immunohistochemistry report of ER and PR were included in this study after informed consent. Patients treated with neoadjuvant chemotherapy and patients with distant metastatic disease at presentation were excluded from the study. In the given time frame, 320 patients satisfied our study criteria. Institutional ethical committee approval was taken.

All mastectomy specimens were fixed in formalin and histopathological examination of paraffin embedded tissues were done after staining with haematoxylin and eosin. Histopathological tumor grading was done using the Elston and Ellis modification of the Scarff Bloom Richardson scoring (Elston and Ellis, 1991). TNM staging was done as per the American Joint Committee on Cancer (AJCC) 7th edition (Edge et al., 2010).

The status of ER and PR were obtained purely on the basis of immunohistochemical staining using standard techniques. ER or PR was considered to be positive if more than or equal to $1 \%$ tumor cell nuclei were immunoreactive.

Age, sex, tumor site, breast involved, tumor size, $\mathrm{T}$ stage, lymph nodal involvement, TNM stage, histological type, histological grade, lymphovascular invasion (LVSI), tumor necrosis and postoperative margin status were noted 
along with the ER and PR status of the breast carcinoma on a proforma.

Statistical analysis:-Data was tabulated in Microsoft Excel 2013 and analysed by using Statistical Package for Social Sciences (SPSS) Version 21. For all statistical analysis, $\mathrm{P}$ value $<0.001$ was considered as significant.

\section{Results}

In our study, 194 out of 320 patients $(60.6 \%)$ with breast cancer were 40 to 60 years of age. 4 out of 320 patients in the study were males. Left breast carcinoma was slightly higher in prevalence than right breast cancer accounting for 164 patients out of $320(51.25 \%)$. The site of tumor in the breast was most commonly the upper outer quadrant in 148patients (46.25\%) (Table 1).

Morphologically, 200 (62.5\%) out of 320 patients

Table 1. Clinical and Morphological Characteristics of Study Population

\begin{tabular}{|c|c|c|c|}
\hline Variables & & $\begin{array}{l}\text { Frequency } \\
(\mathrm{N}=320)\end{array}$ & $\begin{array}{c}\text { Percentage } \\
(\%)\end{array}$ \\
\hline \multirow[t]{3}{*}{ Age } & $<40$ & 82 & 25.6 \\
\hline & $40-60$ & 194 & 60.6 \\
\hline & $>60$ & 44 & 13.8 \\
\hline \multirow[t]{2}{*}{ Sex } & Females & 316 & 98.75 \\
\hline & Males & 4 & 1.25 \\
\hline \multirow[t]{5}{*}{ Tumor Site } & Central & 64 & 20 \\
\hline & Upper Outer & 148 & 46.25 \\
\hline & Lower Inner & 36 & 11.25 \\
\hline & Lower Outer & 12 & 3.75 \\
\hline & Upper Inner & 60 & 18.75 \\
\hline \multirow[t]{2}{*}{ Breast Involved } & Right & 156 & 48.75 \\
\hline & Left & 164 & 51.25 \\
\hline \multirow[t]{3}{*}{ Tumor Size } & $\leq 2 \mathrm{Cm}$ & 36 & 11.3 \\
\hline & $>2-5 \mathrm{Cm}$ & 200 & 62.5 \\
\hline & $>5 \mathrm{Cm}$ & 84 & 26.2 \\
\hline \multirow[t]{4}{*}{ T Stage } & 1 & 32 & 10 \\
\hline & 2 & 164 & 51.3 \\
\hline & 3 & 82 & 25.6 \\
\hline & 4 & 42 & 13.1 \\
\hline \multirow[t]{4}{*}{ N Stage } & No & 160 & 50 \\
\hline & N1 & 98 & 30.6 \\
\hline & $\mathrm{N} 2$ & 26 & 8.1 \\
\hline & $\mathrm{N} 3$ & 36 & 11.3 \\
\hline \multirow{4}{*}{ Histological Types } & IDC NOS & 270 & 84.4 \\
\hline & IPC & 22 & 6.9 \\
\hline & ILC & 22 & 6.9 \\
\hline & MC & 6 & 1.9 \\
\hline \multirow[t]{3}{*}{ Histological Grade } & I & 20 & 6.3 \\
\hline & II & 84 & 26.3 \\
\hline & III & 216 & 67.5 \\
\hline \multirow[t]{2}{*}{ LVSI } & Positive & 42 & 13.1 \\
\hline & Negative & 278 & 86.9 \\
\hline \multirow[t]{2}{*}{ Tumor Necrosis } & Positive & 100 & 31.25 \\
\hline & Negative & 220 & 68.75 \\
\hline \multirow[t]{2}{*}{ Margin Status } & Close/Positive & 68 & 21.25 \\
\hline & Negative & 252 & 78.75 \\
\hline \multirow[t]{2}{*}{ ER Status } & Positive & 180 & 56.25 \\
\hline & Negative & 140 & 43.75 \\
\hline \multirow[t]{2}{*}{ PR Status } & Positive & 170 & 53.1 \\
\hline & Negative & 150 & 46.9 \\
\hline
\end{tabular}

*LVSI = Lymphovascular space invasion, IDC NOS = Infiltrating ductal carcinoma, not otherwise specified, IPC = Invasive papillary carcinoma, ILC = Infiltrating lobular carcinoma, $\mathrm{MC}=$ Mucinous carcinoma had gross pathological tumor size ranging from more than $2 \mathrm{~cm}$ up to $5 \mathrm{~cm} .164$ patients $(51.3 \%)$ had T2 stage tumors and 42 patients $(13.1 \%)$ presented with skin involvement-mostly skin ulceration and peau d' orange. $160(50 \%)$ patients had no lymph node metastases pathologically (Table 1). 94 of the 320 patients presented with pathological TNM Stage IIA (Figure 1).

Infiltrating ductal carcinoma, not otherwise specified, is the most common histological type of breast tumor encountered in $270(84.4 \%)$ out of 320 patients. Other histological types found were mucinous carcinoma, invasive papillary carcinoma and infiltrating lobular carcinoma. According to the modified Scarff Bloom Richardson scoring, 216 patients $(67.5 \%)$ had histological grade III tumors. Lymphovascular space invasion was noted in only 42 patients (13.1\%). 100 out of 320 patients $(31.25 \%)$ showed presence of tumor necrosis histopathologically. 68 patients $(21.25 \%)$ had close or positive postoperative margins (Table 1). In our study, close margin was defined as margin within $5 \mathrm{~mm}$ from the tumor. In most of the margin close or involved patients, it was the posterior margin which was affected.

On immunohistochemistry, $180(56.25 \%)$ and 170 (53.1\%) patients expressed ER and PR positive tumors respectively (Table 1$)$.

On correlating the study variables with ER and PR status of the patients in the study, we obtained a statistically significant association $(\mathrm{p}<0.001)$ between ER, PR status of the tumor with the age of the patient. Also the TNM pathological Stage and histological tumor grade showed significant correlation $(\mathrm{p}<0.001)$ with both ER and PR status. (Table 2).

Table 2. Distribution of Study Variables According to ER and PR Status

\begin{tabular}{|c|c|c|c|c|c|c|c|}
\hline \multicolumn{2}{|l|}{ Variables } & \multirow{2}{*}{$\frac{E R+V E}{36}$} & \multirow{2}{*}{$\frac{\text { ER-VE }}{46}$} & \multirow[t]{2}{*}{$\mathrm{p}$ value } & \multicolumn{2}{|c|}{$P R+V E$ PR-VE } & \multirow[t]{2}{*}{$\mathrm{p}$ value } \\
\hline Age & $\leq 40$ & & & & 36 & 46 & \\
\hline \multirow[t]{2}{*}{ (Years) } & $>40-60$ & 0104 & 90 & \multirow[t]{2}{*}{$<0.001$} & 96 & 98 & \multirow[t]{2}{*}{$<0.001$} \\
\hline & $>60$ & 140 & 4 & & 38 & 6 & \\
\hline \multirow{3}{*}{$\begin{array}{l}\text { Tumor Size } \\
(\mathrm{Cm})\end{array}$} & $\leq 2$ & 20 & 16 & \multirow{3}{*}{0.012} & 18 & 18 & \multirow{3}{*}{0.179} \\
\hline & $>2-5$ & 124 & 76 & & 114 & 86 & \\
\hline & $>5$ & 36 & 48 & & 38 & 46 & \\
\hline \multirow[t]{4}{*}{ pT Stage } & 1 & 20 & 12 & \multirow{4}{*}{0.004} & 18 & 14 & \multirow{4}{*}{0.039} \\
\hline & 2 & 106 & 58 & & 98 & 66 & \\
\hline & 3 & 36 & 46 & & 38 & 44 & \\
\hline & 4 & 18 & 24 & & 16 & 26 & \\
\hline \multirow[t]{4}{*}{ pN Stage } & 0 & 100 & 60 & \multirow{4}{*}{0.002} & 92 & 68 & \multirow{4}{*}{0.003} \\
\hline & 1 & 56 & 42 & & 60 & 38 & \\
\hline & 2 & 6 & 20 & & 6 & 20 & \\
\hline & 3 & 18 & 18 & & 12 & 24 & \\
\hline \multirow[t]{6}{*}{ TNM Stage } & Ia & 12 & 6 & \multirow{6}{*}{$<0.001$} & 10 & 8 & \multirow{6}{*}{$<0.001$} \\
\hline & IIa & 68 & 26 & & 62 & 32 & \\
\hline & $\mathrm{IIb}$ & 44 & 26 & & 50 & 20 & \\
\hline & IIIa & 22 & 40 & & 22 & 40 & \\
\hline & $\mathrm{IIIb}$ & 16 & 24 & & 14 & 26 & \\
\hline & IIIc & 18 & 18 & & 12 & 24 & \\
\hline \multicolumn{8}{|c|}{ Tumor Grade } \\
\hline I & & 16 & 4 & \multirow{3}{*}{$<0.001$} & 16 & 4 & \multirow{3}{*}{$<0.001$} \\
\hline II & & 72 & 12 & & 66 & 18 & \\
\hline III & & 92 & 124 & & 88 & 128 & \\
\hline \multirow[t]{2}{*}{ LVSI } & sitive & 24 & 18 & \multirow[t]{2}{*}{0.9} & 24 & 18 & \multirow[t]{2}{*}{0.576} \\
\hline & gative & 156 & 122 & & 146 & 132 & \\
\hline \multicolumn{8}{|c|}{ Tumor Necrosis } \\
\hline & sitive & 38 & 62 & \multirow[t]{2}{*}{0.003} & 46 & 54 & \multirow[t]{2}{*}{0.085} \\
\hline & gative & 142 & 78 & & 124 & 96 & \\
\hline
\end{tabular}




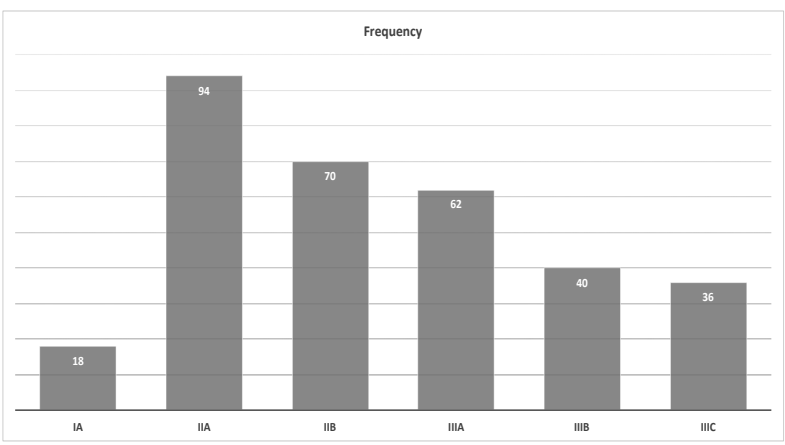

Figure 1. Clustered Column Chart Depicting the Frequency Distribution of Study Population in Various TNM Stages of Breast Cancer

\section{Discussion}

Breast cancer is one of the most frequently diagnosed cancer in developed countries (Siegel et al., 2014). But now, breast cancer incidence has been on a rise in developing countries too, especially in urban areas (Murthy et al., 2009).

Most of the patients were in the age group of 40 to 60 years, with a mean age of 51.4 years. The mean age of breast cancer patients in developed countries is almost one decade higher when compared to Indian studies (Stead et al., 2009; Sandhu et al., 2010). On correlating age with ER and PR status, hormone receptor positivity was found to be more common in elderly patients as has been found in literature (Sofi et al., 2012). Men comprise of only around $1 \%$ of all diagnosed breast cancers (Sedighi et al., 2013). As found in literature as well as the current study, upper outer quadrant is the most common siteof primary breast tumor (Sofi et al., 2012).

Most common histological type of breast cancer was infiltrating ductal carcinoma similar to that found in literature (Shet et al., 2009; Sofi et al., 2012). Most commonly, the tumors were of 2 to $5 \mathrm{~cm}$ in size, as has been also found in other studies (Sofi et al., 2012). 50\% patients in the study had lymph nodal involvement on presentation, which indicates the aggressive nature of the tumors found in Indian population. Though data from developed countries suggest that most of the breast cancer patients do not have any lymph node metastasis, Indian studies have documented higher percentages of lymph nodal involvement in breast cancer patients (Taucher et al., 2003; Sofi et al., 2012; Rao et al., 2013). Most of the patients presented in TNM Stage II as most of the patients had tumor size between 2 to $5 \mathrm{~cm}$ and $50 \%$ of the patients did not have any lymph nodal disease. Both ER and PR status correlated significantly with the stage of the disease, thereby indicating that ER, PR positive tumors were associated with early stage breast tumors. Similar correlation was also found in other studies (Zhou et al., 2014).

An Indian study with 11780 patients of breast cancer, found $70 \%$ of the tumors to be of histological grade III (Shet et al., 2009). Similar results were found in the current study. Alike some other studies, the hormone receptor status in the present study significantly correlated with the histological grade of breast tumors (Sofi et al., 2012; Shet et al., 2009; Ambroise et al., 2011). Similar to a regional study, lymphovascular space invasion was seen in less than $20 \%$ of the patients (Rao et al., 2013). Presence of histologic tumor necrosis has been found to be higher in Indian studies (Rao et al., 2013).

The prevalence of ER and PR expression on immunohistochemistrywere $56.25 \%$ and $53.1 \%$ respectively in the present study as opposed to the $75 \%$ ER and $58 \%$ PR positivity documented in western literature (Rhodes et al., 2000). In India, the prevalence of hormone receptor positivity has been seen to be lower, when compared to western literature (Shet et al., 2009; Ambroise et al., 2011). In a study from Southern India, the prevalence of ER, PR co-positivity was found to be $32 \%$ only (Zubeda et al., 2014). An additional HER2/neu testing in South Indian women with breast cancer demonstrated $46 \%$ of the breast tumors to be triple negative (Zubeda et al., 2014). Triple negative breast cancers in Asian population were found to be associated with younger age of onset, increasing tumor size, increased prevalence of axillary lymph nodal involvement, higher histological grade of tumor and poor prognosis (Ma et al., 2013; Li et al., 2014).

In conclusion, in context of developing countries like India, breast cancer occurs in younger female when compared to the developed world. The proportion of histological high grade breast tumors, lymph node involvement are also high, when compared to the data from developed nations. Percentage of ER and PR expressing breast tumors is lower when compared to that documented in the western countries.ER, PR negative tumors occur more commonly in young breast cancer patients. ER, PR positive tumors are associated with early stage breast cancers. Lack of expression of ER and PR are also associated with higher histological tumor grades. In developing countries like India, though breast cancer is not yet the most common cancer affecting females, as in the developing countries, breast cancer patients in the developing nations present with more aggressive tumors when compared to that of the west.

\section{References}

Ambroise M, Ghosh M, Mallikarjuna VS, Kurian A (2011). Immunohistochemical profile of breast cancer patients at a tertiary care hospital in South India. Asian Pac J Cancer Prev, 12, 625-9.

Breast. In: Edge SB, Byrd DR, Compton CC, et al (2010), eds.: AJCC Cancer Staging Manual. 7th ed. New York, NY: Springer, 347-76.

Elston CW, Ellis IO (1991). Pathological prognostic factors in breast cancer. The value of histological grade in breast cancer: experience from large study with long-term followup. Histopathology, 19, 403-10.

Li CY, Zhang S, Zhang XB, et al (2014). Clinicopathological and prognostic characteristics of triple-negative breast cancer (TNBC) in Chinese patients: A retrospective study. Asian Pac J Cancer Prev, 14, 3779-84.

Ma KK, Chau WW, Wong CHN, et al (2013). Triple negative status is a poor prognostic indicator in Chinese women with breast cancer: a ten year review. Asian Pac J Cancer Prev, 13, 2109-14.

Murthy NS, Chaudhry K, Nadayil D, Agarwal UK, Saxena S 
(2009). Changing trends in incidence of breast cancer: Indian scenario. Indian J Cancer, 46, 73-4.

Rhodes A, Jasani B, Balaton AJ, Barnes DM, Miller KD (2000). Frequency of oestrogen and progesterone receptor positivity by immunohistochemical analysis in 7016 breast carcinomas: Correlation with patient age, assay sensitivity, threshold value, and mammographic screening. J Clin Pathol, 53, 688-96.

Rao C, Shetty J, Kishan Prasad HL (2013). Morphological profile and receptor status in breast carcinoma: an institutional study. J Cancer Res Ther. 9, 44-9.

Stead LA, Lash TL, Sobieraj JE, et al (2009). Triple-negative breast cancers are increased in black women regardless of age or body mass index. Breast Cancer Res, 11, 18.

Shet T, Agrawal A, Nadkarni M, et al (2009). Hormone receptors over the last 8 years in a cancer referral center in India: What was and what is? Indian J Pathol Microbiol, 52, 171-4.

Sandhu DS, Sandhu S, Karwasra RK, Marwah S (2010). Profile of breast cancer at a tertiary care hospital in north India. Indian J Cancer, 47, 16-22.

Sin ghai R, Patil VW, Patil AV (2011). Status of HER-2/neu receptors and $\mathrm{Ki}-67$ in breast cancer of Indian women. Int J App Basic Med Res, 1, 15-9.

Sofi GN, Sofi JN, Nadeem R, et al (2012). Estrogen receptor and progesterone receptor status in breast cancer in relation to age, histological grade, size of lesion and lymph node involvement. Asian Pac J Cancer Prev. 13, 5047-52.

Sedighi A, Hamed EA, Mohammadian K, Behnood S, Kalaghchi B (2013). Clinicopathologic characteristics of male breast cancer: a report of 21 cases in radiotherapy center of hamedan, iran. Asian Pac J Cancer Prev, 14, 7381-3.

Siegel R, Ma J, Zou Z, Jemal A (2014). Cancer statistics 2014. CA Cancer J Clin, 64, 9-29.

Taucher S, Rudas M, Mader RM, et al (2003). Do we need HER$2 /$ neu testing for all patients with primary breast carcinoma? Cancer, 98, 2547-53.

Zhou XL, Fan W, Yang G, Yu MX (2014). The clinical significance of PR, ER, NF-kB, and TNF- $\alpha$ in breast cancer. Dis Markers, 2014, 494581.

Zubeda S, Kaipa PR, Shaik NA, et al (2014). HER2/neu status: A neglected marker of prognostication and management of breast cancer patients in India. Asian Pac J Cancer Prev. 14, 2231-5. 